\title{
Article \\ A Tunable Microstrip Bandpass Filter with Two Concurrently Tuned Transmission Zeros
}

\author{
Mirosław Magnuski (D), Dariusz Wójcik*(D), Maciej Surma (D) and Artur Noga (D)
}

check for

updates

Citation: Magnuski, M.; Wójcik, D.;

Surma, M.; Noga, A. A Tunable

Microstrip Bandpass Filter with Two

Concurrently Tuned Transmission

Zeros. Electronics 2022, 11, 807.

https://doi.org/10.3390/

electronics11050807

Academic Editors: Leonardo Pantoli,

Egidio Ragonese, Paris Kitsos and

Gaetano Palumbo

Received: 12 February 2022

Accepted: 2 March 2022

Published: 4 March 2022

Publisher's Note: MDPI stays neutral with regard to jurisdictional claims in published maps and institutional affiliations.

Copyright: (c) 2022 by the authors. Licensee MDPI, Basel, Switzerland. This article is an open access article distributed under the terms and conditions of the Creative Commons Attribution (CC BY) license (https:// creativecommons.org/licenses/by/ $4.0 /)$.
Department of Electronics, Electrical Engineering and Microelectronics, Silesian University of Technology, Akademicka 16, 44-100 Gliwice, Poland; miroslaw.magnuski@polsl.pl (M.M.); maciej.surma@polsl.pl (M.S.); artur.noga@polsl.pl (A.N.)

* Correspondence: dariusz.wojcik@polsl.pl

\begin{abstract}
In this paper, an electrically small tunable microstrip bandpass filter with two concurrently tuned transmission zeros (TZs) is presented. The filter consists of two coupled resonators and varactors as tuning elements. An application of a multipath coupling network results in TZs on both sides of the passband. The filter controlled by a single voltage has a wide tuning range from $370 \mathrm{MHz}$ to $800 \mathrm{MHz}$ and a low insertion loss ranging from $1.9 \mathrm{~dB}$ to $3.4 \mathrm{~dB}$. To achieve high attenuation in the stopband, two sections of the designed filter were cascaded. Both one-section and two-section filters were validated by measurements. The obtained results are in a very good agreement with simulations.
\end{abstract}

Keywords: tunable bandpass filter; constant fractional bandwidth; single control voltage; microstrip technology

\section{Introduction}

The continuous development of RF and microwave technology forces the research of new filter structures that are adjusted to the requirements of modern equipment. An important role among the different realizations of filters is played by the microstrip bandpass tunable filters, especially those of large tuning range, small size, high stopband attenuation, and low insertion loss in the passband. A common method for designing filters having high slope steepness and high stopband attenuation adopts high-order filter designs, but this approach leads to the large filter dimensions and can be the cause of their large insertion loss [1]. Another widely applied method is the addition to the filter response transmission zeros occurring in the transition or stop bands. This can be achieved in several ways: by adding open/short stubs to the filter network [2,3], by applying defected ground structures [4], by combining bandstop and bandpass filters [5-7], by combining lowpass and highpass filters [8], or by adopting the multipath coupling technique [9-25]. The latter introduces the compensation of the signal crossing from the input to the output of the network. For this purpose, the cross-coupling technique [12-14,20,25], the source load coupling technique $[15-17,19]$, or the mixed coupling technique $[18,21-24]$ is used. The application of the mentioned techniques is especially difficult for those widely tuned filters in which the tuning of the passband and transmission zeros occurs concurrently. Varactors are the most commonly used to tune microstrip filters due to voltage control that is energetically efficient. Therefore, the achievement of concurrent tuning leads to the independent control of several varactors [26-29]. However, filter structures having all varactors tuned with a single voltage can be found in the literature [3,16,17,19,22-24].

The requirements of a wide tuning range, steep slopes, high stopband attenuation, low insertion loss, and small size are difficult to meet simultaneously. Thus, in the case of low-order filters tuned in frequency around the octave, small stopband attenuation up to $30 \mathrm{~dB}[3,19,28,30]$ or small slope steepness [29] is often obtained. On the other hand, 
most filters with large slope steepness achieve a small tuning range [24,31]. Filters having a wide tuning range together with high slope steepness are commonly electrically large $[19,32,33]$. An effective method for improving slope steepness and stopband attenuation in the case of filter sections having small sizes and simple designs is cascading of several sections [32,34-38].

This paper describes a constant fractional bandwidth bandpass filter tuned over a wide frequency range that has two concurrently tuned transmission zeros located on both sides of the passband to improve the steepness of the slopes in the transition bands. The occurrence of transmission zeros is the result of the application of the multipath coupling technique. In Section 2, the lumped elements filter prototype is discussed in detail. The realization of the microstrip tunable filter is shown in Section 3, where its properties are investigated with circuit and full-wave simulations. In Section 4, the cascade connection of two sections of the proposed filter joined with an additional matching circuit is presented. In Section 5, the designed filters are compared with the other filters described in the literature. The filters' parameters were experimentally verified with very good agreement between the simulations and measurements.

\section{Lumped Element Prototype}

Figure 1a shows a lumped element prototype of a triple-coupled double-tuned bandpass filter (TCDTF) proposed in this paper. The filter is built of two identical resonators $\left(C_{1}\right.$, $\left.L_{1}-L_{4}\right)$ and two additional inductors $L_{5}$. The center frequency of the resonators is

$$
f_{0}=\frac{1}{2 \pi \sqrt{\left(L_{1}+L_{2}+L_{\mathrm{eq}}\right) C_{1}}}
$$

where

$$
L_{\text {eq }}=\frac{2 L_{3} L_{4}}{2 L_{3}+L_{4}}
$$

is an equivalent inductance of the coupling PI network built of inductors $L_{3}$ and $L_{4}$. The network introduces the triple inductive coupling within the filter with the coupling coefficient [39]

$$
K=\frac{L_{\mathrm{eq}}}{L_{1}+L_{2}+L_{\mathrm{eq}}} .
$$

The proposed filter is a modification of the double-coupled double-tuned filter (DCDTF) shown in Figure 1b, invented by the authors and described in their previous publication [40]. The example characteristics of both filters are compared in Figure 2 for $f_{0}=489 \mathrm{MHz}$ and $K=0.05$. The TCDTF parameters are $C_{1}=3.6 \mathrm{pF}, L_{1}=23 \mathrm{nH}, L_{2}=5 \mathrm{nH}, L_{3}=1.75 \mathrm{nH}$, $L_{4}=2.5 \mathrm{nH}, L_{5}=12.25 \mathrm{nH}$, and the DCDTF parameters are $C_{1}=3.6 \mathrm{pF}, L_{1}=23 \mathrm{nH}$, $L_{2}=5 \mathrm{nH}, L_{3}=0.73 \mathrm{nH}$. Both filters have the same equivalent inductance of the coupling network. The center frequencies of both passband filters are close to the center frequencies of their resonators. The application of an additional inductance $L_{4}$ in the network shown in Figure 1a results in a transmission zero appearance below its center frequency. This increases the slope steepness of this filter response in the lower transition band compared to the network depicted in Figure $1 \mathrm{~b}$. The additional inductances $L_{5}$ transform the source and load impedance upwards. Its influence on the filter characteristics is shown in Figure 3. As can be seen, the $L_{5}$ inductances affect the insertion loss, stopband attenuation, and the return loss of the network without changing the position of the two transmission zeros and the center frequency. Increasing the $L_{5}$ inductance improves the steepness of the slope within the lower transition band of the filter, the in-band flatness, and the out-of-band attenuation. 
(a)

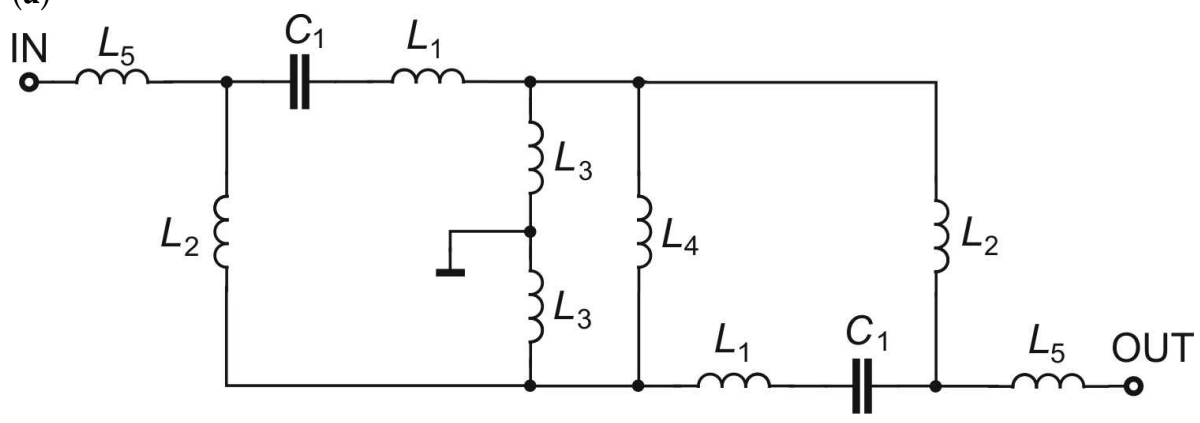

(b)

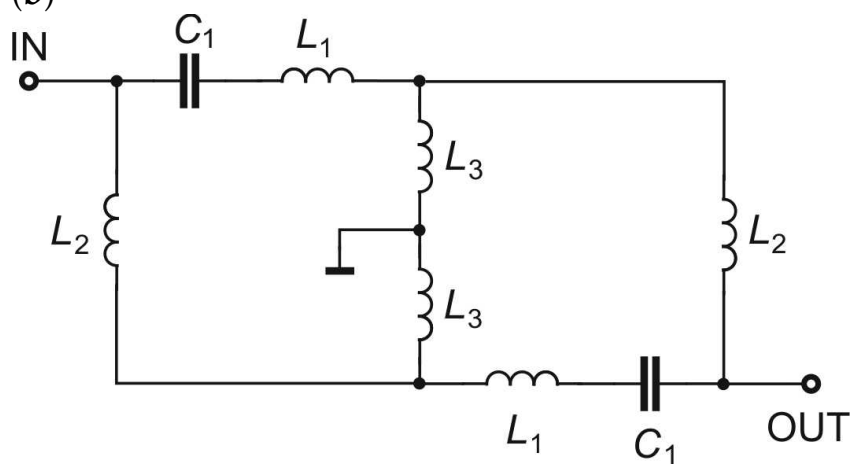

Figure 1. Lumped element bandpass filters: (a) TCDTF (this work), (b) DCDTF (described in [40]).

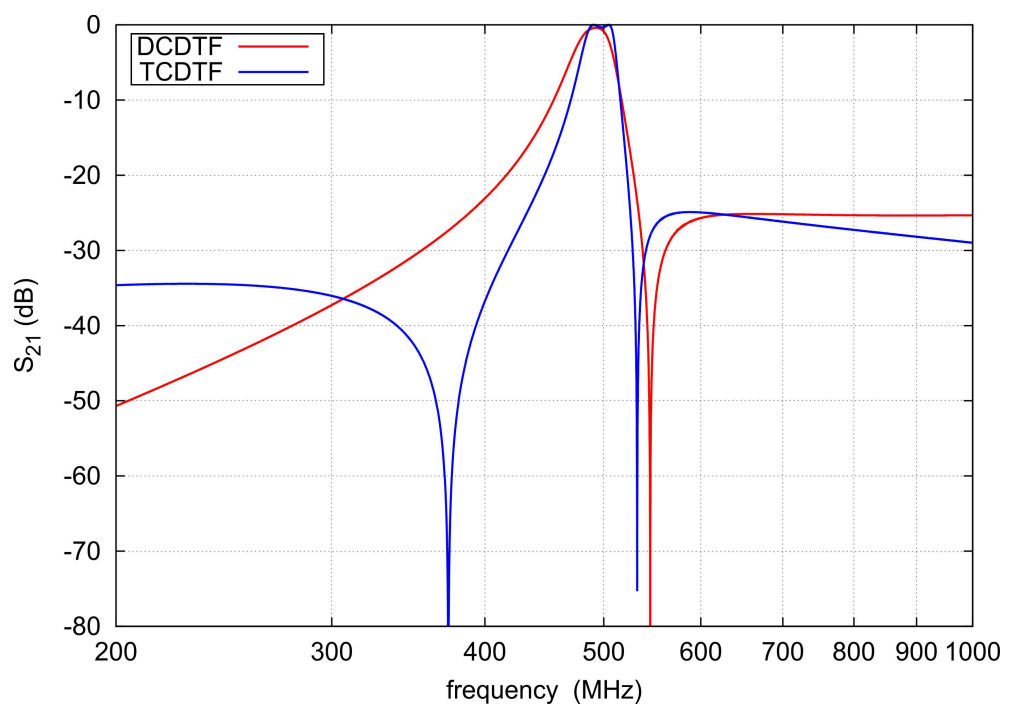

Figure 2. $S_{21}$ response of the TCDTF (in this work) and DCDTF ([40]).

The frequencies of the transmission zeros are given by the following equation:

$$
f_{1,2}=\sqrt{\frac{2 L_{1} L_{3}+2 L_{2} L_{3}+2 L_{2} L_{4} \pm L_{3} L_{4} \sqrt{L_{4}\left[L_{3}^{2} L_{4}+4 L_{2}^{2}\left(2 L_{3}+L_{4}\right)-4 L_{2} L_{3}\left(L_{3}-L_{4}\right)\right]}}{8 \pi^{2} C_{1}\left\{L_{1}^{2} L_{3}+L_{2} L_{3}\left(L_{2}+2 L_{4}\right)+L_{1}\left[L_{3} L_{4}+2 L_{2}\left(L_{3}+L_{4}\right)\right]\right\}}} .
$$

The influence of other filter components on the position of transmission zeros is shown in Figures 4-6. The figures show the results of the parametric analysis performed for a constant coupling coefficient $K=0.05$ and a constant value of frequency $f_{0}=489 \mathrm{MHz}$. The results shown in Figure 4 were obtained by varying the values of inductances $L_{3}$ and $L_{4}$ with a constant equivalent inductance $L_{\mathrm{eq}}=1.46 \mathrm{nH}$. 


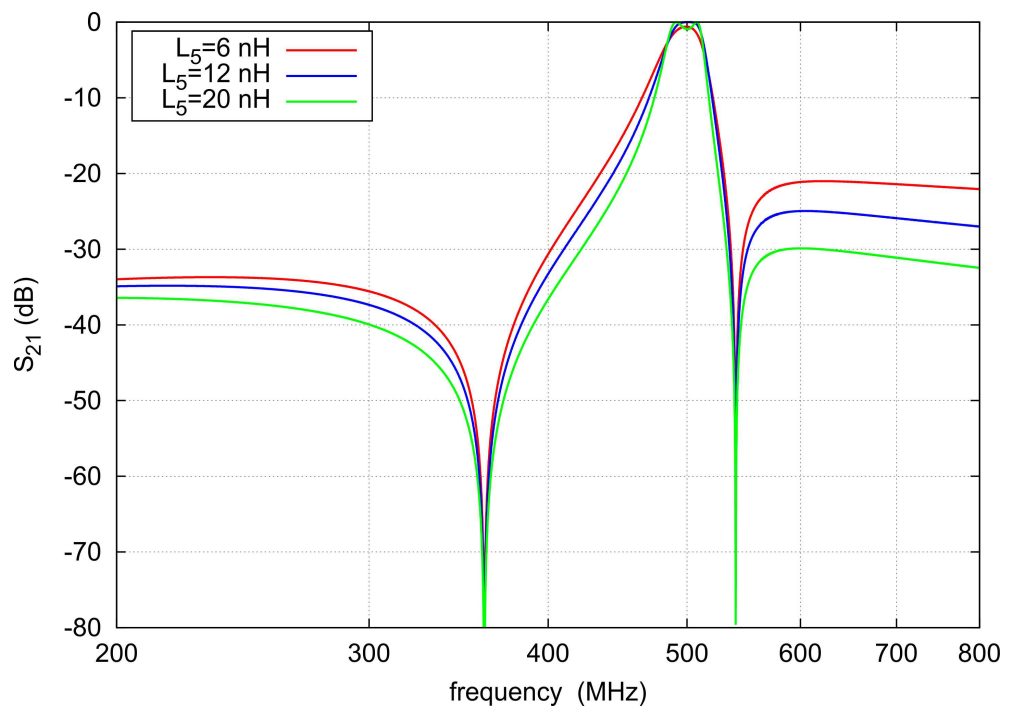

Figure 3. Effect of the $L_{5}$ inductance on the filter response.

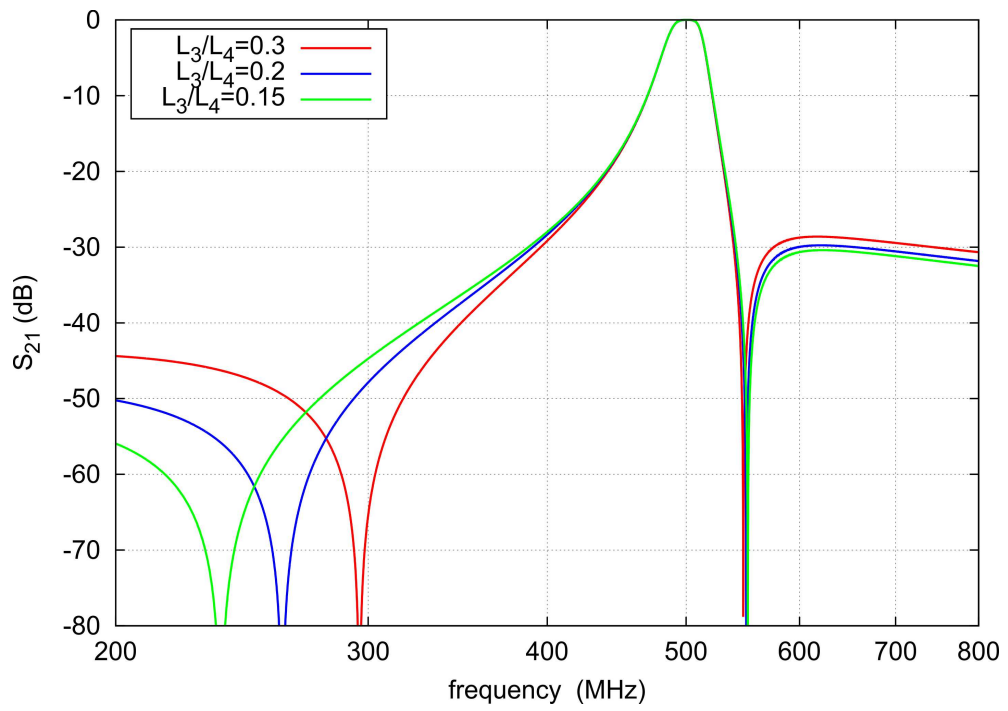

Figure 4. Influence of the $L_{3} / L_{4}$ ratio on the lower TZ position.

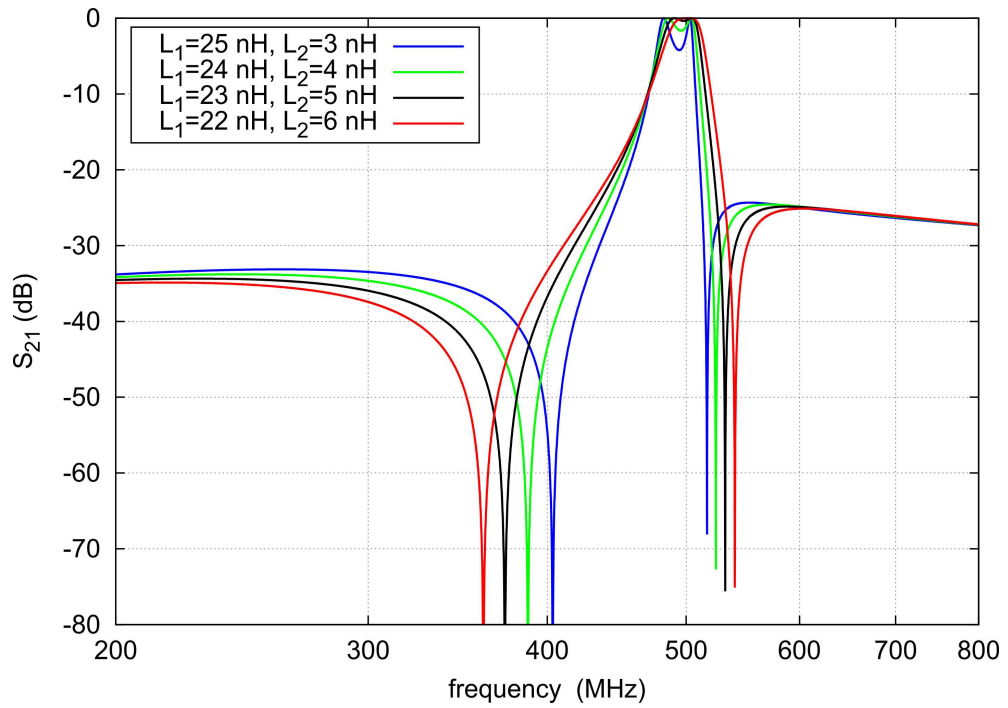

Figure 5. Influence of $L_{1}$ and $L_{2}$ inductances on the $s_{21}$ parameter. 
It can be seen that the response of the filter within its passband and the position of the right transmission zero remain practically unchanged. The position of the left transmission zero depends on the ratio of inductances $L_{4}$ to $L_{3}$. Increasing the ratio causes the shift of the left TZ towards higher frequencies together with a weak reduction of the attenuation within the stopband. Figures 5 and 6 show the effects of varying $L_{1}$ and $L_{2}$ on the shape of the frequency response and the matching of the filter. The test was carried out by changing the values of inductances $L_{1}$ and $L_{2}$ while keeping their sum constant and equal to $28 \mathrm{nH}$ in order to maintain the center frequency constant. Decreasing the value of the inductance $L_{2}$ causes the appearance of ripples of $s_{11}$ and $s_{21}$ in the passband and lowers the mean value of the return loss. Synchronously, the transmission zero frequencies approach each other, increasing the slope steepness of $s_{21}$ in the transition bands. The out-of-band attenuation of the filter remains virtually unchanged.

The initial inductances of $L_{1}, L_{2}, L_{\mathrm{eq}}$ were determined as for an ordinary dual-tuned network having the coupling coefficient 0.05 , the load impedance $70 \Omega$, and a center frequency of $400 \mathrm{MHz}$. Then, the inductances $L_{3}$ and $L_{4}$ were found to achieve particular TZ frequencies. Finally, the inductance $L_{5}$ was selected to obtain the transformation of $50 \Omega$ port impedance to filter load impedance of $70 \Omega$.

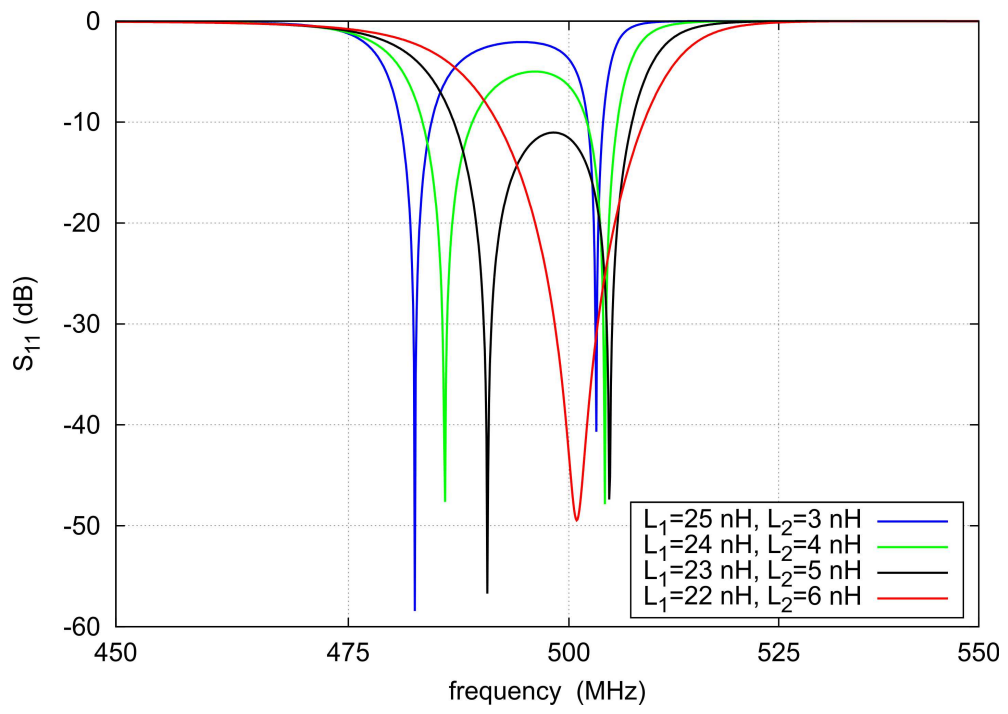

Figure 6. Influence of $L_{1}$ and $L_{2}$ inductances on the $s_{11}$ parameter.

\section{Tunable Microstrip Filter}

In this section, the microstrip realization of a tunable triple-coupled double-tuned filter is presented. The assumed filter tuning range is $400 \mathrm{MHz}$ to $800 \mathrm{MHz}$. The network in Figure 7 was performed on a Rogers 5870 substrate of $\varepsilon_{r}=2.33$ and thickness $h=1.5 \mathrm{~mm}$. The inductances $L_{1}-L_{5}$ of the lumped element prototype are replaced by the sections TL1-TL5 of the transmission lines, the parameters of which are given in Table 1 . The $L_{3}$ is replaced by the TL3 transmission line grounded by two vias. The TL3 parameters were found considering the contribution of the two vias estimated as $0.2 \mathrm{nH}$. The line lengths $l$ and their characteristic impedances $Z_{0}$ are related to the inductances $L_{1}-L_{5}$ by the equation:

$$
\omega L=Z_{0} \tan \beta l \quad \beta l=\frac{2 \pi l}{\lambda} \ll 1 \text { for } f_{\max }
$$

which describes the input reactance of the shorted transmission line. All the transmission lines are electrically short for the highest filter operating frequency $f_{\max }$. Each capacitor $C_{1}$ is replaced by a push-pull connection of eight 1 SV280 varactors that have a capacitance variation $1.3-5.5 \mathrm{pF}$, a lead inductance of $0.4 \mathrm{nH}$, and series resistance $R_{s}=0.44 \Omega$ each. This approach reduced the overall series resistance to $0.22 \Omega$ and the lead inductance to $0.2 \mathrm{nH}$ of the reactor. The varactor groups are connected between the TL1a and TL1b 
line segments. The control voltage $V_{\mathrm{c}}$ is applied to the varactors through the resistors of $R_{\mathrm{c}}=33 \mathrm{k} \Omega$ with the application of the decoupling capacitors $C_{\mathrm{c}}=100 \mathrm{pF}$.

Table 1. Elements of the filters from Figures 7 and 8.

\begin{tabular}{ccc}
\hline Line & $\mathbf{Z}_{\mathbf{0}}(\boldsymbol{\Omega})$ & $\boldsymbol{\beta} \mathbf{( \mathbf { d e g } )} \boldsymbol{*}^{*}$ \\
\hline TL1a & 138 & 3.25 \\
TL1b & 138 & 7.75 \\
TL2 & 101 & 4.8 \\
TL3 & 75 & 1.7 \\
TL4 & 91 & 6.6 \\
TL5 & 138 & 10.1 \\
\hline
\end{tabular}

*-calculated at $370 \mathrm{MHz}$.

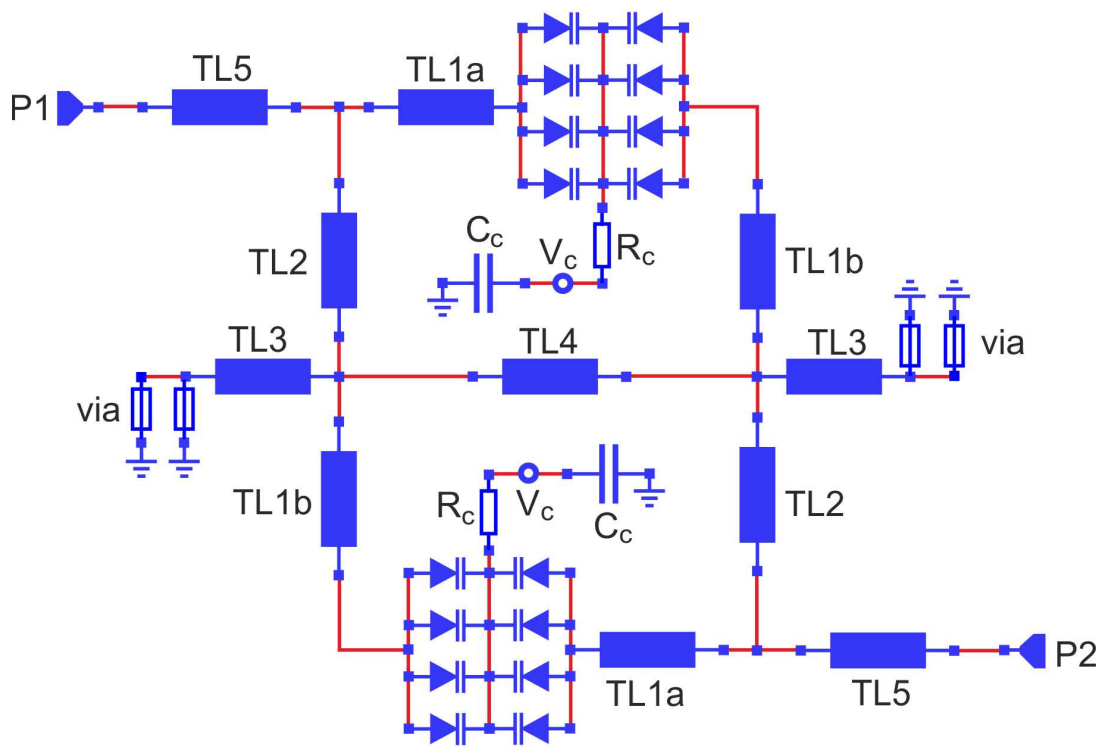

Figure 7. Transmission line implementation of the tunable TCDTF.

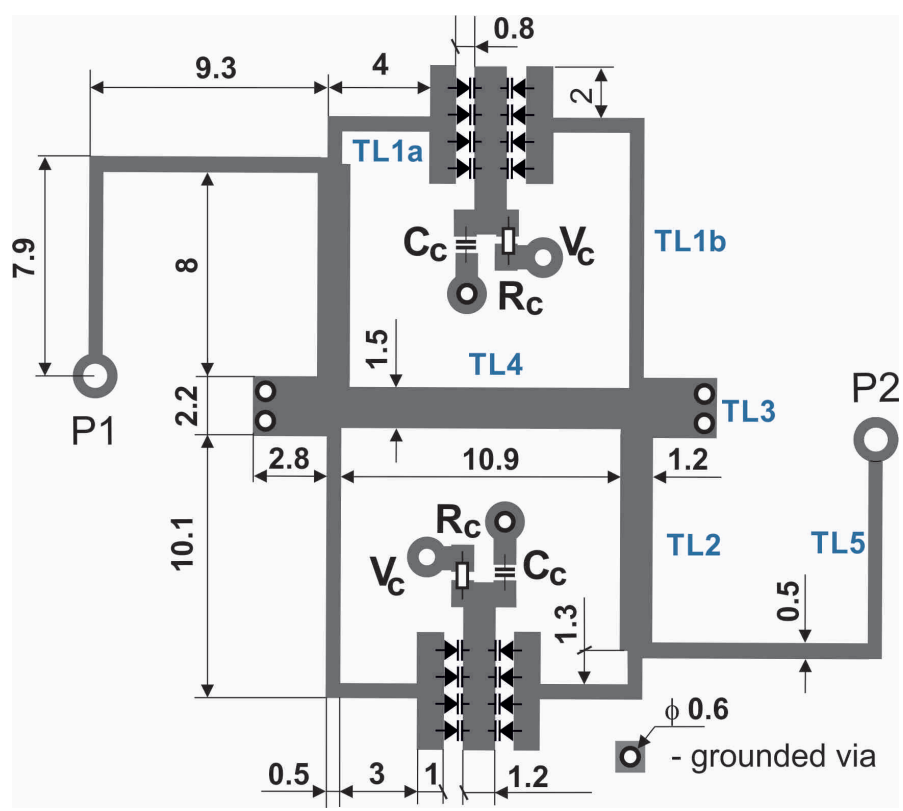

Figure 8. Layout of the proposed tunable bandpass filter (all dimensions in $\mathrm{mm}$ ). 
Figure 8 shows the layout of the designed filter with the dimensions of all the individual lines marked. The topology of the filter simplifies its compact realization by placing the varactor polarization networks within the unused inner surfaces of the resonators. The picture of the completed prototype fabricated in the standard PCB technology is shown in Figure 9. The dimensions of the filter are $30 \times 35 \mathrm{~mm}$ including SMA connectors.

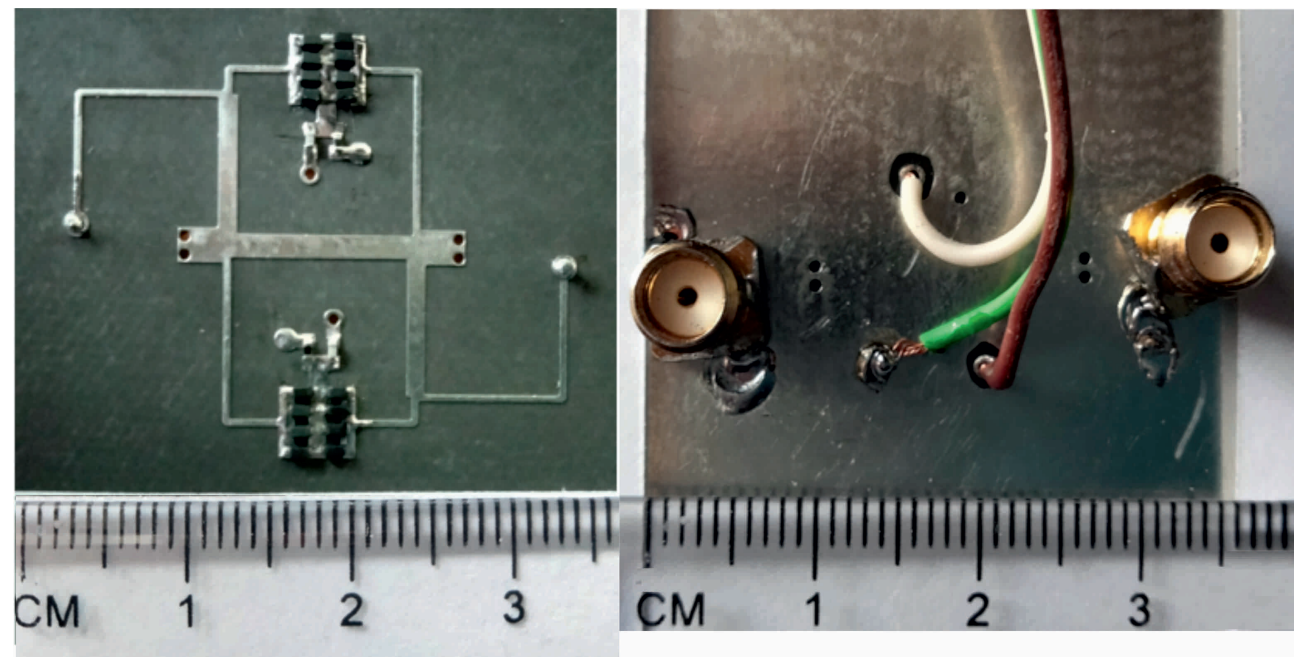

Figure 9. Photo of the fabricated prototype of the tunable microstrip bandpass filter.

The filter parameters were measured with the Agilent PNA-L N5230A vector network analyzer. The filter was also simulated in the frequency domain with the CST Microwave Studio software. For simulation purposes, each varactor was modeled as a series connections of the capacitance, the series resistance, and the lead inductance. During the simulations, the capacitances were tuned experimentally to achieve the same values of the center frequencies as those measured.

In Figures 10 and 11, the comparison between the measurements (solid lines) and simulations (dashed lines) of the scattering parameters in the frequency range of $200 \mathrm{MHz}$ to $1000 \mathrm{MHz}$ is shown for the control voltage variation from $1 \mathrm{~V}$ to $18 \mathrm{~V}$. As one can see, a very good agreement is observed, which shows that manufacturing the proposed filter in standard PCB technology provides sufficient mechanical accuracy. The measured tuning range extends from $370 \mathrm{MHz}$ to $800 \mathrm{MHz}$. Within the whole tuning range, the bandwidth of the filter varies monotonically from $23 \mathrm{MHz}$ to $48 \mathrm{MHz}$, but the relative bandwidth remains practically unchanged. The insertion loss is better than $3.4 \mathrm{~dB}$ at $370 \mathrm{MHz}$ and decreases monotonically up to $1.9 \mathrm{~dB}$ at $800 \mathrm{MHz}$. It can be reduced by increasing the coupling coefficient or applying varactors having lower equivalent serial resistance. The minimal return loss is about $19 \mathrm{~dB}$ at frequency $370 \mathrm{MHz}$, increases to $35 \mathrm{~dB}$ at $600 \mathrm{MHz}$, and then decreases to $25 \mathrm{~dB}$ at $800 \mathrm{MHz}$. Tuning of the filter weekly affects the attenuation introduced by both transmission zeros. It is about $72 \mathrm{~dB}$ for the lower $\mathrm{TZ}$ and more than $47 \mathrm{~dB}$ for the upper TZ. Figure 12 shows the results of $s_{21}$ measurements in the frequency range extended to $3 \mathrm{GHz}$. As can be seen, the value of out-of-band attenuation close to $25 \mathrm{~dB}$ is maintained up to $1.6 \mathrm{GHz}$, which is next to double the maximum tuning frequency. Over $1.6 \mathrm{GHz}$, the attenuation decreases due to a parasitic passband that occurs at $2.5 \mathrm{GHz}$, which is determined solely by the filter topology and is practically independent of the control voltage. 


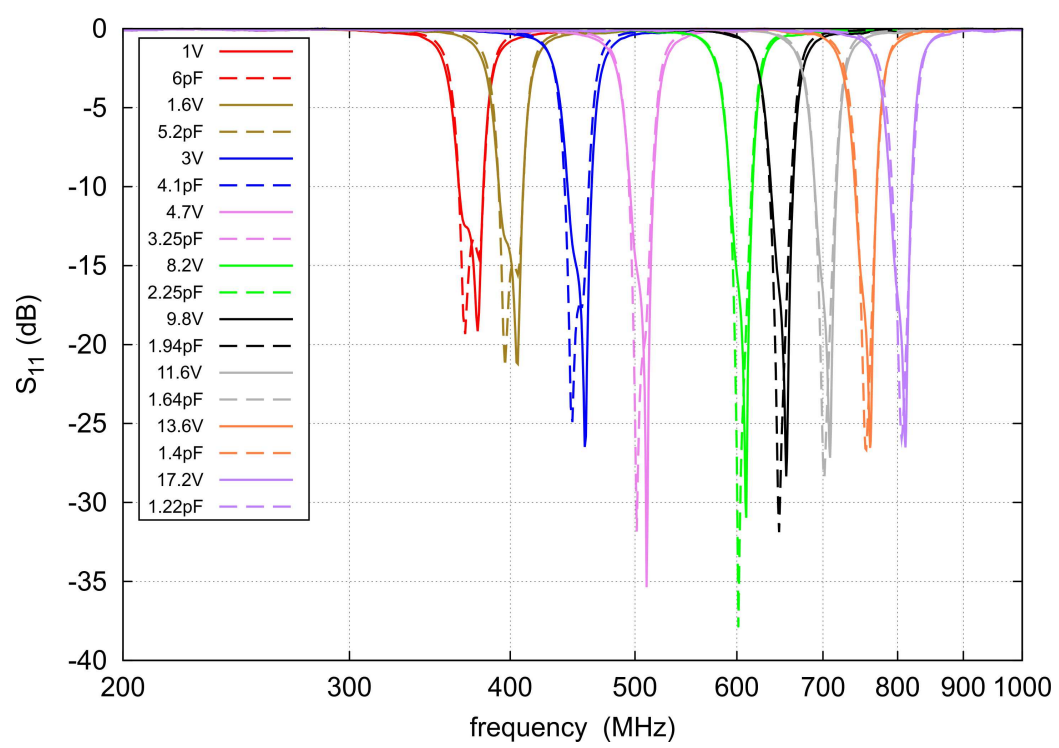

Figure 10. Measured (solid lines) and simulated (dashed lines) $s_{11}$ of the proposed tunable bandpass filter for the nine selected control voltages.

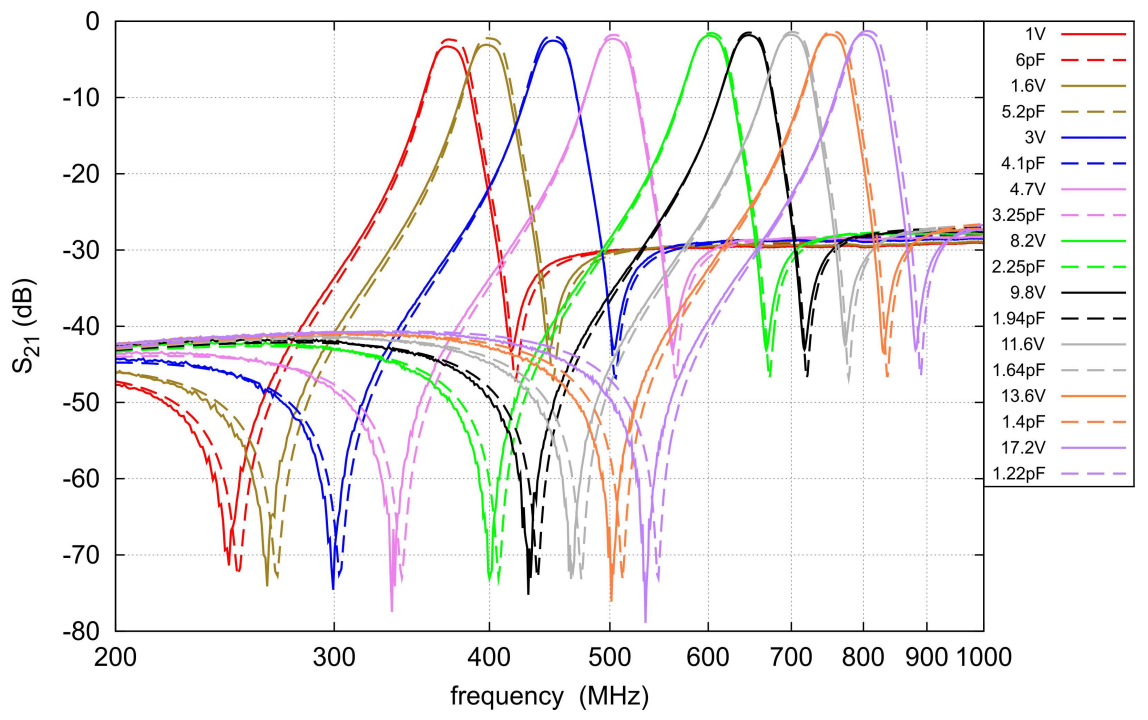

Figure 11. Measured (solid lines) and simulated (dashed lines) $s_{21}$ of the proposed tunable bandpass filter for the nine selected control voltages.

Figures 13-15 show the current density distributions at $504 \mathrm{MHz}, 340 \mathrm{MHz}$, and $563 \mathrm{MHz}$ determined by the simulations. The frequencies correspond to the center frequency and both TZs depicted in the filter response shown in Figure 11 for the control voltage of $4.7 \mathrm{~V}$. For the center frequency $504 \mathrm{MHz}$, while the energy is transmitted from input to output with little insertion loss, the current amplitudes are very similar in both resonators. The occurrence of transmission zeros at $340 \mathrm{MHz}$ and $563 \mathrm{MHZ}$ is the result of the compensation of currents entering the particular nodes of the network. At node $C$ located at the junction of TL1a, TL2, and TL5 lines on the output port side of the filter, the compensation occurs at both TZ frequencies. This effect is also illustrated in Figure 16, where the amplitude of the current $I_{11}$ flowing along the line TL5 and the phase difference of the currents $I_{9}$ and $I_{10}$ flowing along the lines TL1a and TL2 are shown as functions of frequency. It can be seen that at both frequencies $340 \mathrm{MHz}$ and $563 \mathrm{MHz}$ the current $I_{11}$ is close to zero and the phase shift between the currents $I_{9}$ and $I_{10}$ is $180 \mathrm{deg}$. It can be further seen in Figure 14 that, at lower TZ frequency, the compensation of the currents $I_{4}$ and $I_{8}$, which excite the second resonator, is also present. This effect is possible due to 
the coupling realized by means of the TL4 line. The amplitudes of the currents flowing through nodes A and B are shown in Figures 17 and 18, respectively. For both nodes, the currents $I_{4}$ and $I_{8}$ are practically identical at the lower TZ frequency of $340 \mathrm{MHz}$ and they are about $15 \mathrm{~dB}$ smaller than for higher TZ of $563 \mathrm{MHz}$. Due to the double compensation, the attenuation achieved for the lower TZ is about $25 \mathrm{~dB}$ higher than for the upper TZ. It should be mentioned that for the $340 \mathrm{MHz}$ frequency, the current $I_{6}$ is practically cancelled.

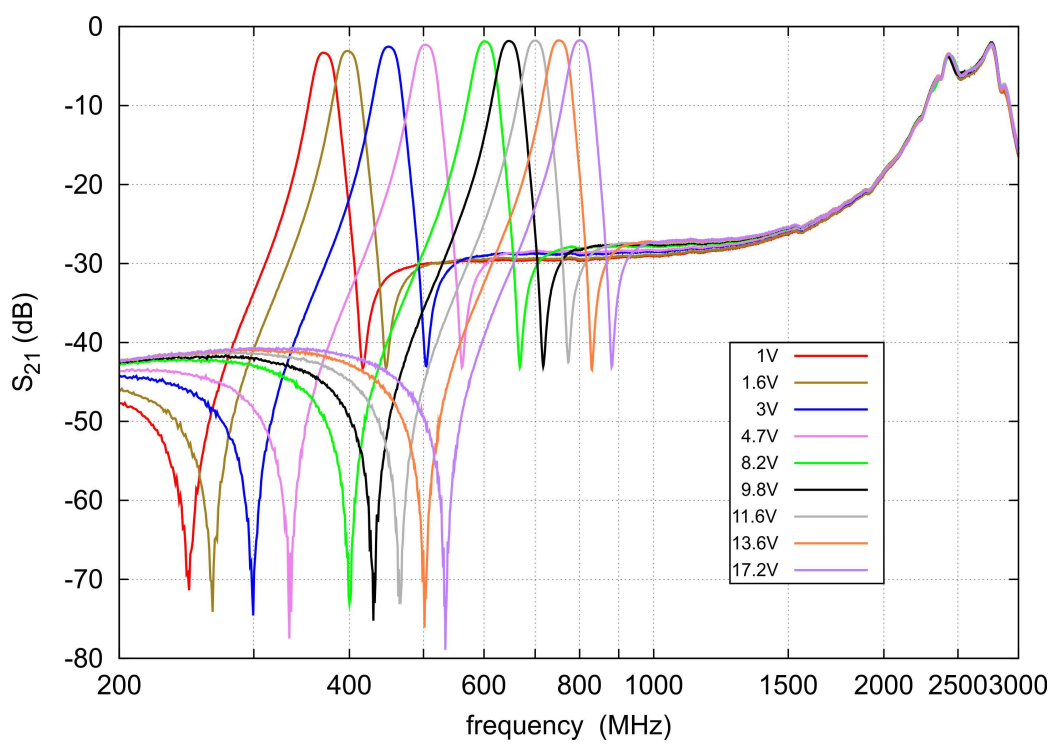

Figure 12. Broadband measurements of the $s_{21}$ for the proposed filter for the nine selected control voltages.

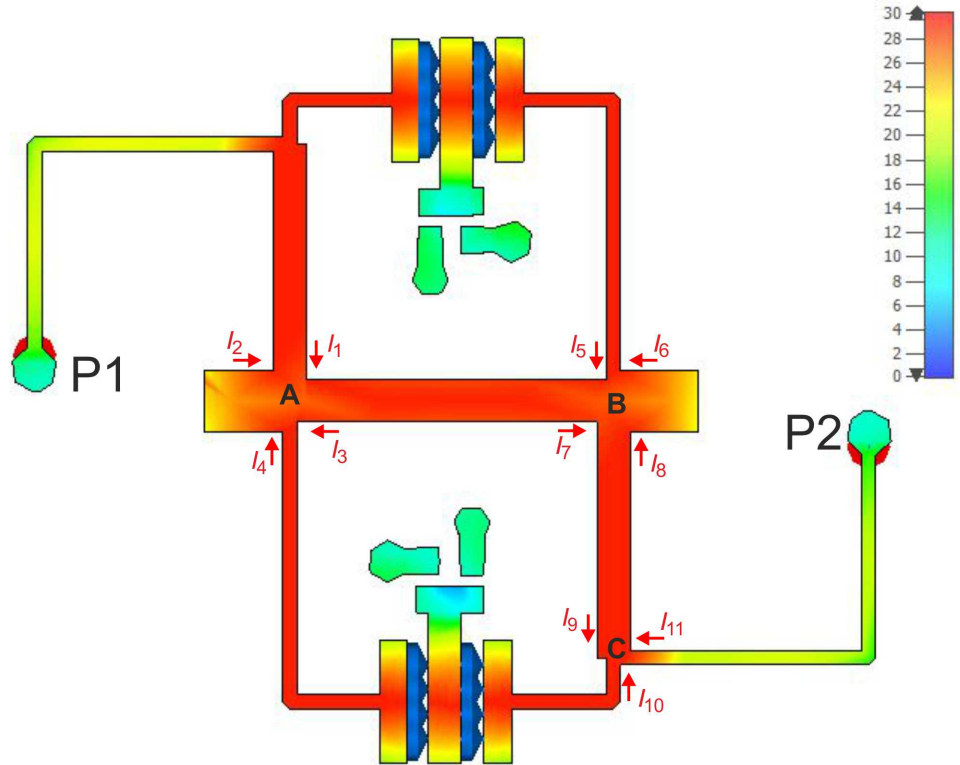

Figure 13. Current density distribution at the centre frequency ( $504 \mathrm{MHz})$ of the filter. 


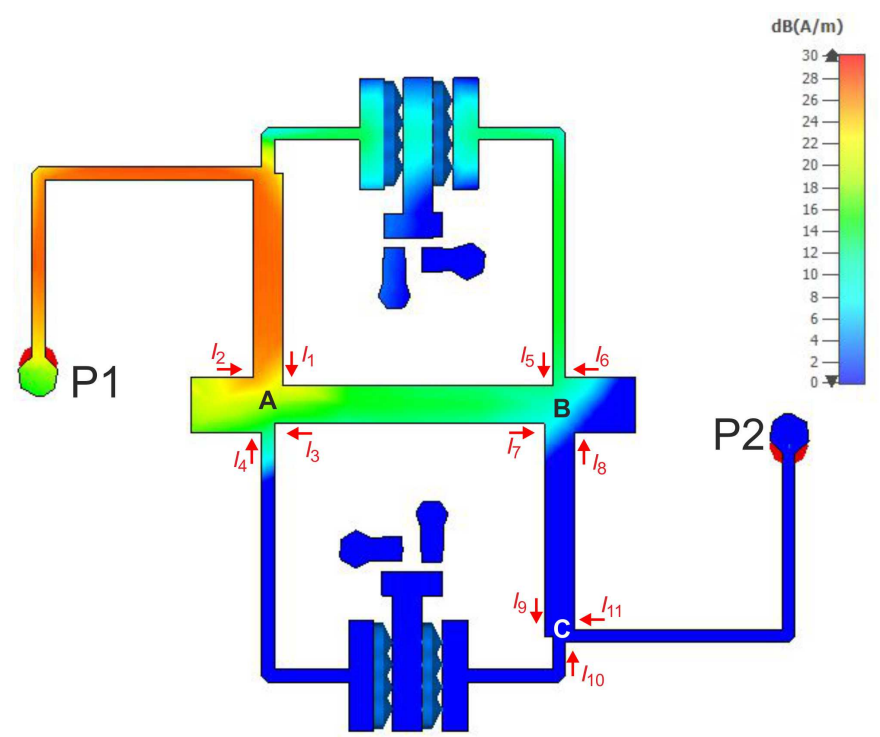

Figure 14. Current density distribution at the lower TZ frequency $(340 \mathrm{MHz})$.

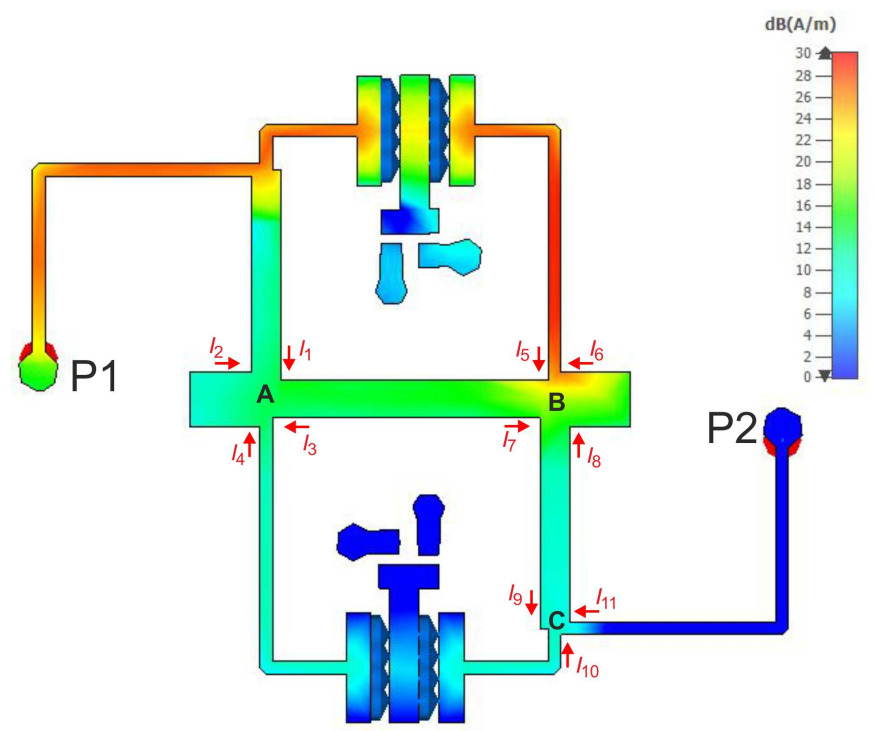

Figure 15. Current density distribution at the upper TZ frequency (563 MHz).

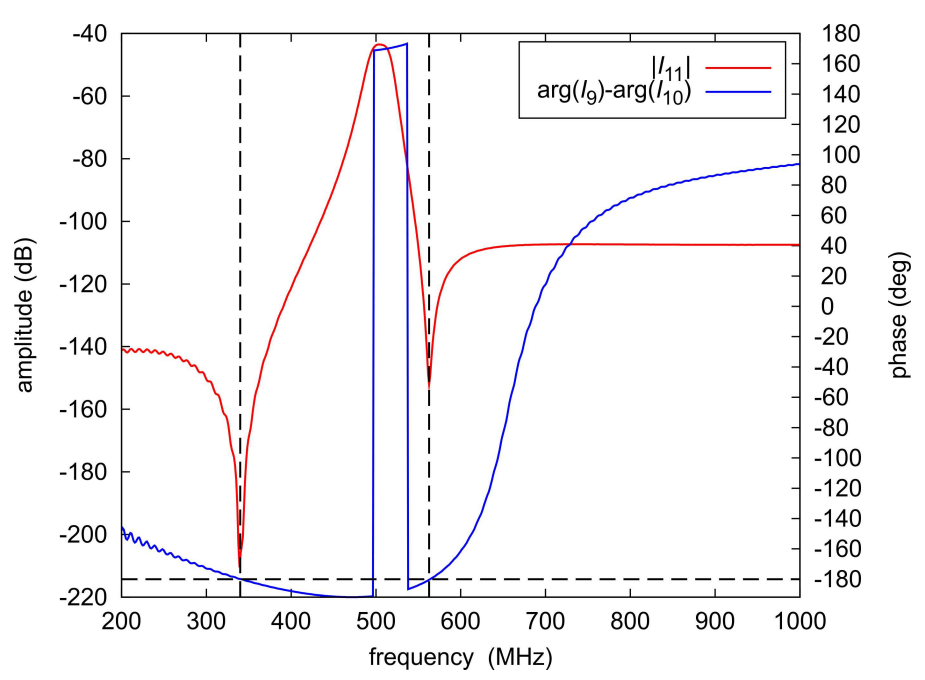

Figure 16. $I_{11}$ current amplitude and the phase difference of the $I_{9}$ and $I_{10}$ currents at the node $\mathrm{C}$ for $V_{c}=4.7 \mathrm{~V}$. 




Figure 17. Amplitudes of the currents flowing through the node A.

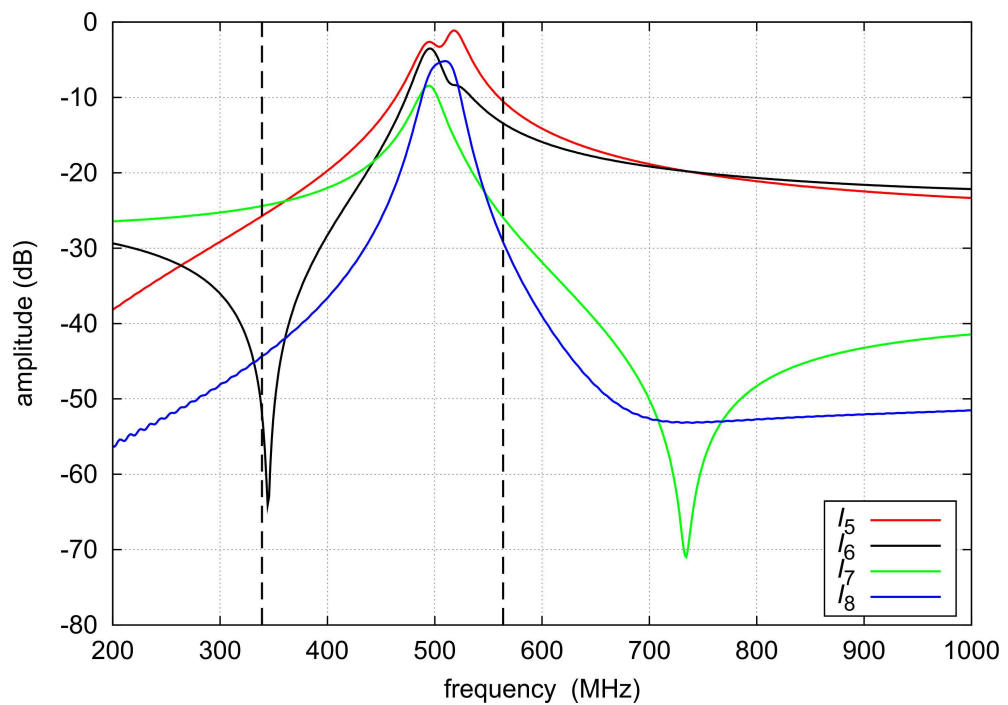

Figure 18. Amplitudes of the currents flowing through the node B.

\section{Two-Section Filter}

Due to the small size of the described filter, an easy way to further improve the attenuation in the stopband and to increase the steepness slope in the transition band is to cascade two sections. Two possible realizations of such a filter are shown in Figure 19. Obtaining the desired frequency characteristics requires reducing the mutual electromagnetic coupling between two sections placed close to each other and decreasing the loading of the first section by the second. The load reduction is achieved by moving the ports used for the interconnection of the two sections towards the ground to the position near the center of the LT2 line. This is equivalent to the upward transformation of the load impedance of interconnected resonators. To improve the shape of the passband response of the filter, an additional T-network is used for section interconnection. It consists of three transmission line sections that act as two series inductors of $2.1 \mathrm{nH}$ and one parallel inductor of $6 \mathrm{nH}$. The values of the inductors were chosen to improve the insertion loss and return loss in the whole tuning range of the filter. Both sections of the filter are tuned concurrently with a single voltage. 


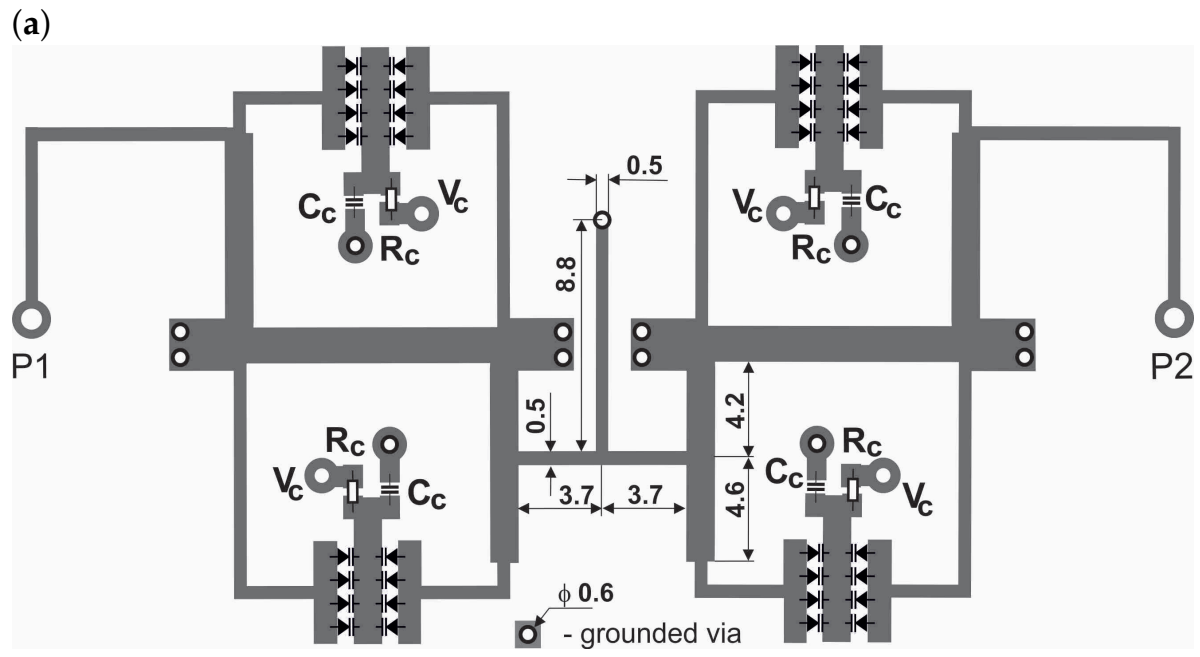

(b)

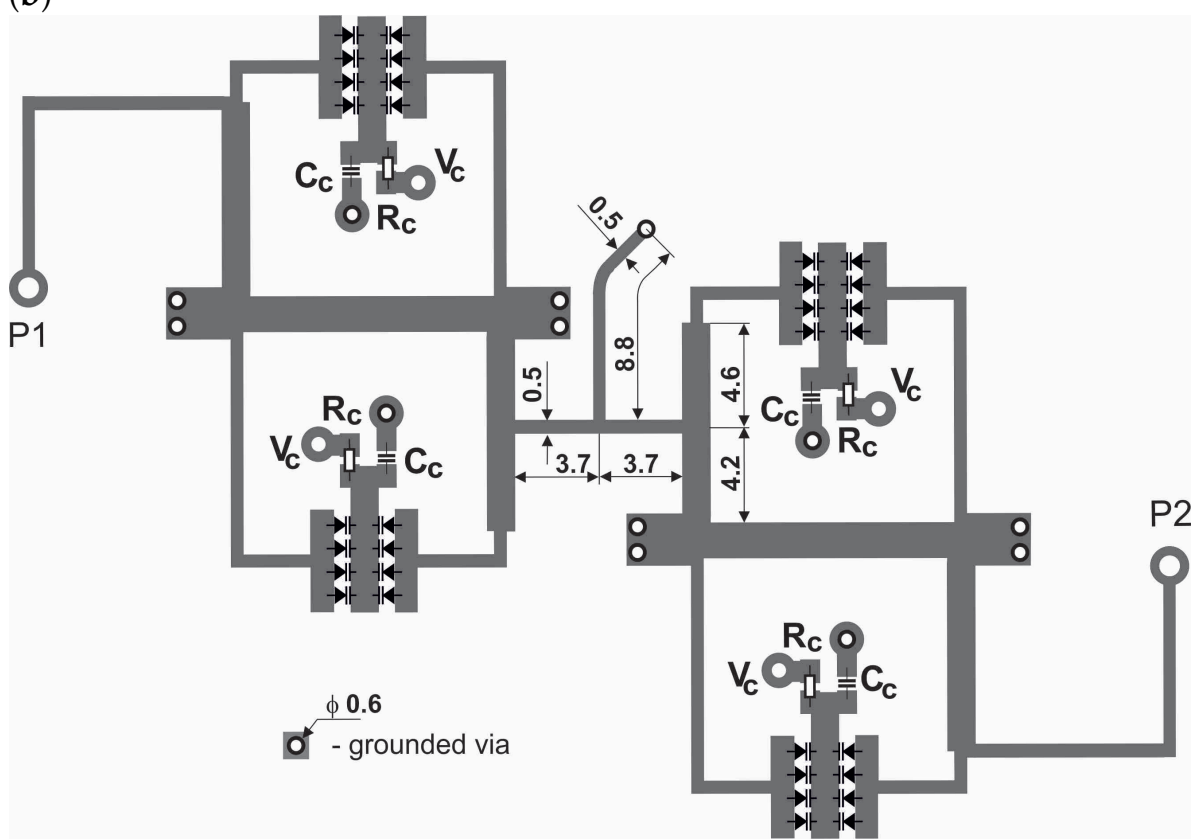

Figure 19. Layout of the cascade connection of the two filter sections (all dimensions in $\mathrm{mm}$ ): (a) layout A, (b) layout B.

The mutual coupling between the sections usually leads to a significant deterioration of the filter properties, especially in the stopband. To illustrate this phenomenon, two layouts of the cascaded filter shown in Figure 19 were analyzed. In the first design (see Figure 19a), the sections were doubled and displaced in parallel by $20 \mathrm{~mm}$. In the second design (Figure 19b) the mutual coupling between the sections was reduced by applying two sections of layouts being mirror image one of the other together with the parallel displacement by $20 \mathrm{~mm}$ and a perpendicular shift of $10 \mathrm{~mm}$.

The results of $s_{21}$ simulations performed for both layouts are shown in Figure 20 for three center frequencies. It can be seen that the strong mutual coupling between the sections present in the layout of Figure 19a leads to a deterioration of the attenuation in the transition and stop bands and TZs disappearance. In the case of the second layout, the effect of coupling is much weaker and does not lead to essential degradation of the filter properties. In $s_{21}$ there are observed deep TZs, and the attenuation is practically twice as high (in $\mathrm{dB}$ ) as for the single filter section. 




Figure 20. Simulated $s_{21}$ performed for the two layouts shown in Figure 19.

The photo of the fabricated prototype of the two cascaded sections is shown in Figure 21. Figures 22 and 23 show a comparison of the measured and simulated scattering parameters of the cascade connection of the two filter sections for the selected control voltages. In the operating band, the measured $s_{11}$ is below $-9.5 \mathrm{~dB}$ and $s_{21}$ varies from $-6.9 \mathrm{~dB}$ at $380 \mathrm{MHz}$ to $-3.5 \mathrm{~dB}$ at $790 \mathrm{MHz}$. Within the whole tuning range, the bandwidth of the filter varies monotonically from $17.5 \mathrm{MHz}$ to $35.5 \mathrm{MHz}$. The relative bandwidth remains unchanged. Figure 24 shows the $s_{21}$ measured over a wider frequency range. The attenuation for frequencies below the passband is about $80 \mathrm{~dB}$, while above the passband it is about $55 \mathrm{~dB}$ to $1.3 \mathrm{GHz}$. As in the case of a single section, an additional passband near $2.5 \mathrm{GHz}$ existing regardless of the control voltage value is observed.

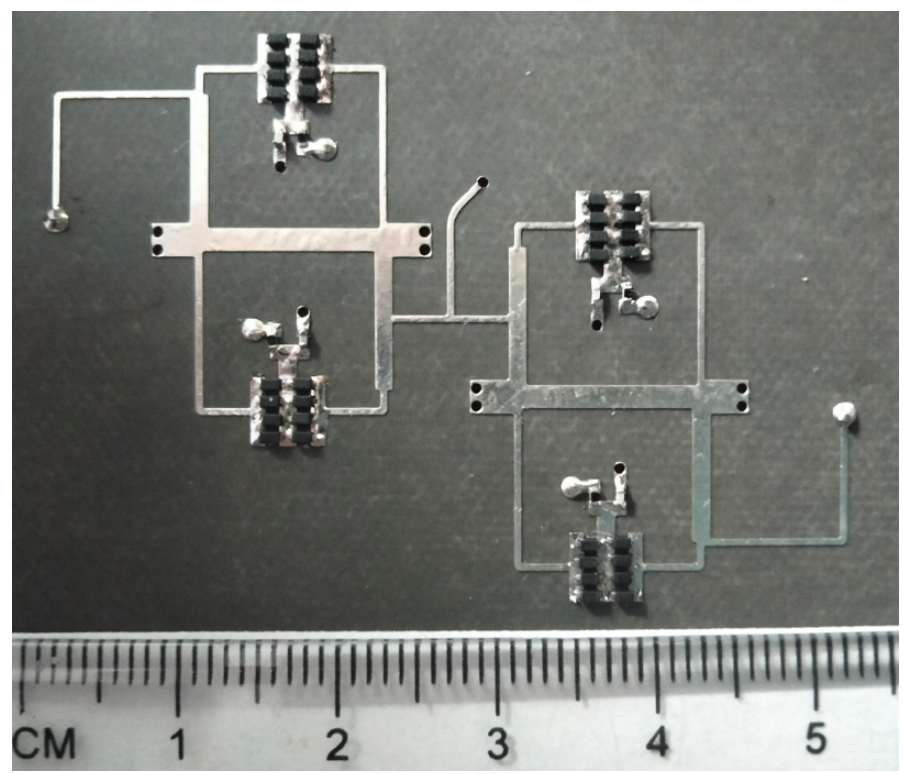

Figure 21. Photo of the cascade connection of the two filter sections. 


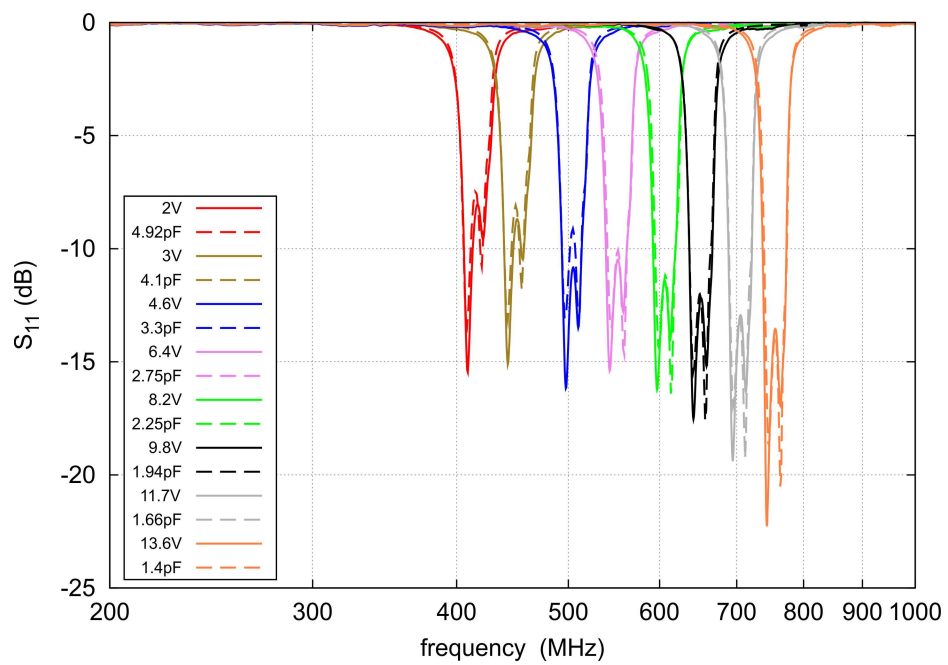

Figure 22. Measured (solid lines) and simulated (dashed lines) $s_{11}$ of the cascade connection of the two filter sections for the eight selected control voltages.

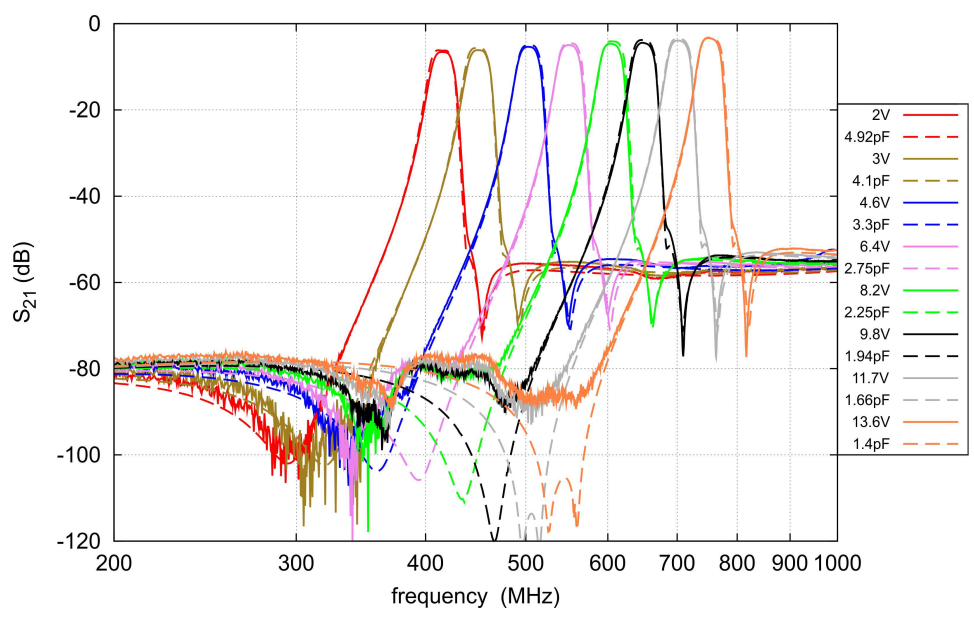

Figure 23. Measured (solid lines) and simulated (dashed lines) $s_{21}$ of the cascade connection of the two filter sections for the eight selected control voltages.

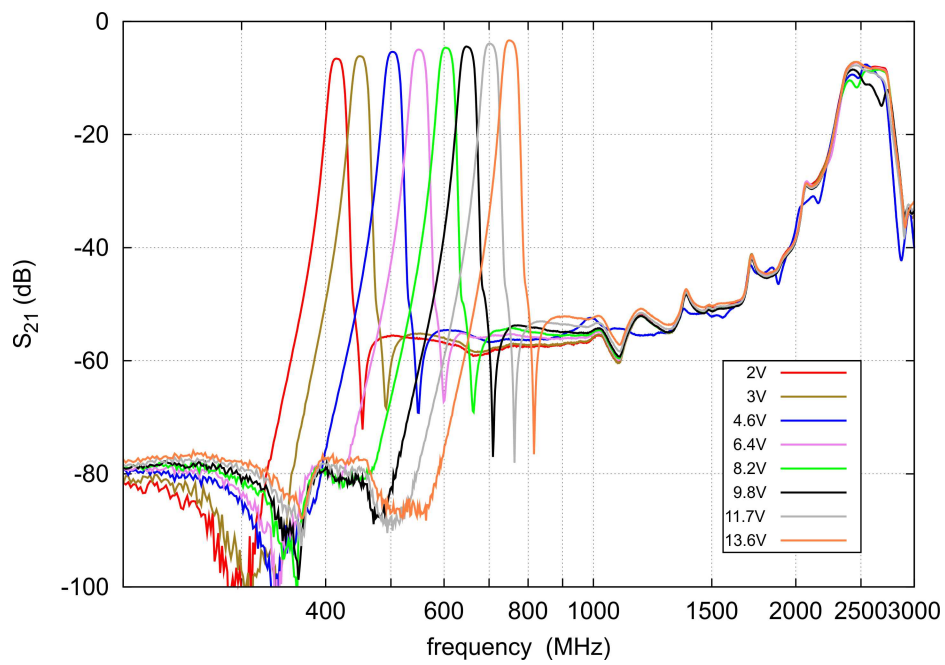

Figure 24. $S_{21}$ of the cascade connection of the two filter sections measured in the wide frequency band for the eight selected control voltages. 


\section{Discussion}

Table 2 compares the proposed single section microstrip tuned TCDTF with other filters reported in the literature that feature at least two TZs. The parameters of the tuning range, the tuning range factor $\left(f_{\max } / f_{\min }\right)$, bandwidth (BW), insertion loss (IL), electrical size, the number of TZs (NTZs), insertion loss in the bandstop ( $\mathrm{IL}_{\mathrm{BS}}$ ), and the number of control voltages (NV) were compared. Filter dimensions are expressed in the guided wavelength $\left(\lambda_{g}\right)$ at the lowest operating frequency. The proposed filter has a constant fractional bandwidth as the filters reported in $[22,24,25]$. The filters $[3,17,26]$ have a constant absolute bandwidth. The TCDTF has the second widest tuning range factor. Only the filter described in [19] is better in this respect, but it occupies an area almost 15 times larger. Most filters, including the proposed, have similar insertion losses not exceeding $4 \mathrm{~dB}$. The filters $[24,26]$ have a significantly larger IL. The out-of-band attenuation of a single TCDTF is about $26 \mathrm{~dB}$, which is a typical value but $15 \mathrm{~dB}$ worse than the best filters [22,23]. Most of the compared filters are tuned with a single voltage. The filter described in [26] is tuned with five voltages, which allows for a constant absolute bandwidth over the full tuning range. A clear advantage of the proposed TCDTF over the benchmark filters is the smallest occupied area being half of the area of the smallest reference filter area [24].

Table 2. Comparison between the proposed and the reference filters.

\begin{tabular}{|c|c|c|c|c|c|c|c|c|}
\hline Ref. & f (GHz) & $f_{\max } / f_{\min }$ & BW & IL (dB) & $\begin{array}{c}\text { Size }^{*} \\
\left(\lambda_{g} \times \lambda_{g}\right)\end{array}$ & NTZs & $\mathrm{IL}_{\mathrm{BS}}(\mathrm{dB})$ & NV \\
\hline$[3]$ & $1.15-2$ & 1.74 & $\begin{array}{l}115 \pm 4 \mathrm{MHz} \\
(5.9-9.6 \%)\end{array}$ & $2.4-3.6$ & $0.06 \times 0.24$ & 2 & $<25$ & 1 \\
\hline [16] & $0.97-1.53$ & 1.57 & - & $2-4.2$ & $0.09 \times 0.1$ & 4 & $<30$ & 1 \\
\hline [17] & $1.6-2.27$ & 1.41 & $\begin{array}{c}137 \pm 2 \mathrm{MHz} \\
(6-8.5 \%)\end{array}$ & $1.99-4.17$ & $0.5 \times 0.4$ & 2 & $<30$ & 1 \\
\hline [19] & $0.75-1.87$ & 2.49 & $\begin{array}{l}\text { 75-285 MHz } \\
(10-15.2 \%)\end{array}$ & $1.2-4.2$ & $0.38 \times 0.13$ & 2 & $<24$ & 1 \\
\hline [22] & $0.89-1.13$ & 1.27 & $\begin{array}{c}39-54 \mathrm{MHz} \\
(4.4-4.8 \%)\end{array}$ & $3.2-4.3$ & $0.5 \times 0.35$ & 2 & $<40$ & 1 \\
\hline [23] & $0.89-1.13$ & 1.67 & $\begin{array}{l}12-23 \mathrm{MHz} \\
(2.75-3.2 \%)\end{array}$ & $1.34-2.92$ & $0.16 \times 0.14$ & 2 & $<40$ & 1 \\
\hline [24] & $1.22-1.72$ & 1.41 & $\begin{array}{c}\text { 61-103 MHz } \\
\quad(5-6 \%)\end{array}$ & $3-4.9$ & $0.05 \times 0.12$ & 3 & $<35$ & 1 \\
\hline [25] & $0.79-1.59$ & 2.01 & $\begin{array}{c}55-111 \mathrm{MHz} \\
(7 \%)\end{array}$ & $1.3-2.1$ & $0.16 \times 0.11$ & 2 & $<20$ & 3 \\
\hline [26] & $1.1-2.1$ & 1.9 & $\begin{array}{c}40 \mathrm{MHz} \\
(1.9-3.6 \%)\end{array}$ & $4.4-6.1$ & $0.06 \times 0.27$ & 2 & $<25$ & 5 \\
\hline This work & $0.37-0.8$ & 2.16 & $\begin{array}{c}23-48 \mathrm{MHz} \\
(6 \%)\end{array}$ & $1.9-3.4$ & $0.05 \times 0.06$ & 2 & $<26$ & 1 \\
\hline
\end{tabular}

*-calculated for the lowest operating frequency (given in the second column).

Table 3 compares the parameters of the filter constructed from two TCDTF sections with other two-section filters reported in the literature. As for the single filter, the resulting tuning range is the second widest. At the cost of increased to $6.9 \mathrm{~dB}$ insertion loss, an out-of-band attenuation greater than $52 \mathrm{~dB}$ is obtained, which is $12 \mathrm{~dB}$ higher than the following filter [35]. The greatest advantage of the presented filter is that the aforementioned parameters were achieved despite the smallest dimensions among all comparable two-section filters. 
Table 3. Comparison between the cascaded TCDTF and the two-section reference filters.

\begin{tabular}{|c|c|c|c|c|c|c|}
\hline Ref. & f (GHz) & $f_{\max } / f_{\min }$ & BW & IL (dB) & $\begin{array}{c}\text { Size * } \\
\left(\lambda_{g} \times \lambda_{g}\right)\end{array}$ & $\mathrm{IL}_{\mathrm{BS}}(\mathrm{dB})$ \\
\hline [35] & $0.7-1$ & 1.42 & $\begin{array}{c}39-68 \mathrm{MHz} \\
(5.5-6.8 \%)\end{array}$ & $4.4-6.4$ & $0.5 \times 0.56$ & $<40$ \\
\hline [36] & $1.7-2.5$ & 1.47 & $\begin{array}{c}38-156 \mathrm{MHz} \\
(3.4-6.2 \%)\end{array}$ & $<3.3$ & $1.29 \times 0.51$ & $<21.5$ \\
\hline [37] & $0.119-0.239$ & 2 & $\begin{array}{c}23-42 \mathrm{MHz} \\
(17.5-19.3 \%)\end{array}$ & $<2.41$ & - & $<28$ \\
\hline$[38]$ & $2.6-3.35$ & 1.29 & $\begin{array}{c}109-181 \mathrm{MHz} \\
(4.2-5.4 \%)\end{array}$ & $3.1-3.7$ & $1.35 \times 0.9$ & $<39$ \\
\hline This work & $0.38-0.79$ & 2.08 & $\begin{array}{c}17.5-35.5 \mathrm{MHz} \\
(4.6 \%)\end{array}$ & $3.5-6.9$ & $0.075 \times 0.1$ & $<52$ \\
\hline
\end{tabular}

- calculated for the lowest operating frequency (given in the second column).

\title{
6. Conclusions
}

This paper describes the tunable constant fractional bandwidth triple-coupled doubletuned bandpass filter. The proposed filter due to two concurrently tuned transmission zeros placed on the left and right sides of its bandpass has increased the slope steepness in both the transition bands. It has a wide tuning range spreading from $370 \mathrm{MHz}$ to $800 \mathrm{MHz}$ together with the insertion loss and out-of-band attenuation comparable to the other filters of similar class. It is worth noting that the location of the parasitic upper passband of the filter is independent of the control voltage. The main advantage of the filter is the small electrical size, which justifies the application of the cascade connection of two filter sections to improve the out-of-band attenuation and steepness of the slopes in the transition bands. It should also be emphasized that the area occupied by the cascade of two TCDR filters is only $14 \%$ greater than that of the single filter described in [24], which is the smallest reference single section filter.

Author Contributions: Conceptualization, D.W., M.S. and A.N.; methodology, D.W. and M.S.; validation, M.S., M.M. and A.N.; formal analysis, D.W. and M.M.; investigation, A.N. and M.S.; resources, M.S. and M.M.; data curation, A.N. and M.S.; writing-original draft preparation, D.W. and A.N.; writing - review and editing, M.M. and A.N.; visualization, A.N.; supervision, D.W. All authors have read and agreed to the published version of the manuscript.

Funding: The results presented in this contribution are an outcome of statutory activities of the Department of Electronics, Electrical Engineering and Microelectronics of Silesian University of Technology financed by the Polish Ministry of Science and Higher Education.

Institutional Review Board Statement: This research received no external funding.

Conflicts of Interest: The authors declare no conflict of interest.

\author{
Abbreviations \\ The following abbreviations are used in this manuscript: \\ BPF Bandpass filter \\ BW Bandwidth \\ DCDTF Double-coupled double-tuned filter \\ IL Insertion loss \\ IL $_{\mathrm{BS}} \quad$ Insertion loss in bandstop \\ RF Radio frequency \\ TCDTF Triple-coupled double-tuned filter \\ TZ Transmission zero
}




\section{References}

1. Hong, J.-S.; Lancaster, M.J. Microstrip Filters for RF/Microwave Applications, 1st ed.; John Wiley \& Sons: New York, NY, USA, 2001.

2. Wu, Y.; Cui, L.; Zhuang, Z.; Wang, W.; Liu, Y.T. A simple planar dual-band bandpass filter with multiple transmission poles and zeros. IEEE Trans. Circuits Syst. II Exp. Briefs 2018, 65, 56-60. [CrossRef]

3. Lu, D.; Barker, N.S.; Tang, X. A Simple frequency-agile bandpass filter with predefined bandwidth and stopband using synchronously tuned dual-mode resonator. IEEE Microw. Wirel. Compon. Lett. 2017, 27, 983-985. [CrossRef]

4. Qiao, H.; Guo, D.; Mou, J.; Li, M.; Ma, Z.; Lv, X. HIS-based bandpass filter with improved upper-stopband performance. Electron. Lett. 2018, 54, 363-364. [CrossRef]

5. Saeedi, S.; Lee, J.; Sigmarsson, H.H. Tunable, high-Q, substrate-integrated, evanescent-mode cavity bandpass-bandstop filter cascade. IEEE Microw. Wirel. Compon. Lett. 2016, 26, 240-242. [CrossRef]

6. Sigmarsson, H.H.; Naglich, E.; Lee, J.; Peroulis, D.; Chappell, W. Tunable bandpass and bandstop filter cascade for dynamic pole allocation. In Proceedings of the 2012 IEEE International Symposium on Antennas and Propagation, Chicago, IL, USA, 8-14 July 2012.

7. Yang, W.; Allen, W.N.; Psychogiou, D.; Peroulis, D. Tunable bandpass-bandstop filter cascade for VHF applications. In Proceedings of the 2016 IEEE 17th Annual Wireless and Microwave Technology Conference (WAMICON), Clearwater, FL, USA, 11-13 April 2016.

8. Wei, Z.; Yang, T.; Chi, P.-L.; Zhang, X.; Xu, R. A 10.23-15.7-GHz varactor-tuned microstrip bandpass filter with highly flexible reconfigurability. IEEE Trans. Microw. Theory Technol. 2021, 69, 4499-4509. [CrossRef]

9. Du, T.; Guan, B.; Zhang, P.; Gu, Y.; Wei, D. An intrinsically switched tunable CABW/CFBW bandpass filter. Electronics 2021, 10, 1318.

10. Lin, W.; Zhou, K.; Wu, K. Tunable bandpass filters with one switchable transmission zero by only tuning resonances. IEEE Microw. Wirel. Compon. Lett. 2021, 31, 105-108. [CrossRef]

11. Yildirim, N.; Sen, O.A.; Karaaslan, M.; Pelz, D. A revision of cascade synthesis theory Covering cross-coupled filters. IEEE Trans. Microw. Theory Technol. 2002, 50, 1536-1543. [CrossRef]

12. Cameron, R.J. General coupling matrix synthesis methods for Chebyshev filtering functions. IEEE Trans. Microw. Theory Technol. 1999, 47, 433-442. [CrossRef]

13. Schuster, C.; Kamrath, F.; Miek, D.; Polat, E.; Boe, P.; Frank, L.; Kienemund, C.; Jakoby, R.; Maune, H.; Hoft, M. Fully reconfigurable bandpass with continuously tunable center frequency and bandwidth featuring a constant filter characteristic. In Proceedings of the 2020 German Microwave Conference (GeMiC), Cottbus, Germany, 9-11 March 2020; pp. 236-239.

14. Tian, D.; Feng, Q.; Xiang, Q. Synthesis applied 4th-order constant absolute bandwidth frequency-agile bandpass filter with cross-coupling. IEEE Access 2018, 6, 72287-72294. [CrossRef]

15. Amari, S. Direct synthesis of folded symmetric resonator filters with source-load coupling. IEEE Microw. Wirel. Compon. Lett. 2001, 11, 264-266. [CrossRef]

16. Gao, L.; Rebeiz, G.M. A 0.97-1.53-GHz tunable four-pole bandpass filter with four transmission zeroes. IEEE Microw. Wirel. Compon. Lett. 2019, 29, 195-197. [CrossRef]

17. Zhou, W.-J.; Chen, J.-X. High-selectivity tunable balanced bandpass filter with constant absolute bandwidth. IEEE Trans. Circuits Syst. II Exp. Briefs 2017, 64, 917-921. [CrossRef]

18. Chu, Q.-X.; Wang, H. A compact open-loop filter with mixed electric and magnetic coupling. IEEE Trans. Microw. Theory Technol. 2008, 56, 431-439. [CrossRef]

19. Lu, D.; Tang, X.; Barker, N.S.; Feng, Y. Single-band and switchable dual-/single-band tunable BPFs with predefined tuning range, bandwidth, and selectivity. IEEE Trans. Microw. Theory Technol. 2018, 66, 1215-1227. [CrossRef]

20. Li, X.; Zou, C.; Xiang, Q. Fourth-order electrical tunable microstrip LC cross-coupled bandpass filter. In Proceedings of the Photonics \& Electromagnetics Research Symposium, Rome, Italy, 17-20 June 2019; pp. 2076-2079.

21. Shen, G.; Che, W.; Feng, W.; Wang, C. Realization of multiple transmission zeroes for bandpass filters with simple inline topology. IEEE Trans. Circuits Syst. II Exp. Briefs 2020, 67, 1029-1033. [CrossRef]

22. Ohira, M.; Hashimoto, S.; Ma, Z.; Wang, X. Coupling-matrix-based systematic design of single-DC-bias-controlled microstrip higher order tunable bandpass filters with constant absolute bandwidth and transmission zeros. IEEE Trans. Microw. Theory Technol. 2019, 67, 118-128. [CrossRef]

23. Cai, J.; Chen, J.-X.; Zhang, X.-F.; Yang, Y.-J.; Bao, Z.-H. Electrically varactor-tuned bandpass filter with constant bandwidth and self-adaptive transmission zeros. IET Microw. Antennas Propag. 2017, 11, 1542-1548. [CrossRef]

24. Gao, L.; Lin, T.-W.; Rebeiz, G.M. Design of tunable multi-pole multi-zero bandpass filters and diplexer with high selectivity and isolation. IEEE Trans. Circuits Syst. I Reg. Pap. 2019, 66, 3831-3842. [CrossRef]

25. Fan, M.; Song, K.; Zhu, Y.; Fan, Y. Compact bandpass-to-bandstop reconfigurable filter with wide tuning range. IEEE Microw. Wirel. Compon. Lett. 2019, 29, 198-200. [CrossRef]

26. Chen, C.-F.; Wang, G.-Y.; Li, J.-J. Microstrip switchable and fully tunable bandpass filter with continuous frequency tuning range. IEEE Microw. Wirel. Compon. Lett. 2018, 28, 500-502. [CrossRef]

27. Lee, T.-C.; Lee, J.; Peroulis, D. Dynamic bandpass filter shape and interference cancellation control utilizing bandpass-bandstop filter cascade. IEEE Trans. Microw. Theory Technol. 2015, 63, 2526-2539. [CrossRef] 
28. Kingsly, S.; Kanagasabai, M.; Alsath, M.G.N.; Shrivastav, A.K.; Subbaraj, S.; Selvam, Y.P.; Sivasamy, R.; Ramanarao, Y.V. Compact frequency and bandwidth tunable bandpass-bandstop microstrip filter. IEEE Microw. Wirel. Compon. Lett. 2018, 28, 786-788. [CrossRef]

29. Chen, X.; Wu, Y.; Yang, Y.; Wang, W. Simple coupled-line tunable bandpass filter with wide tuning range. IEEE Access 2020, 8 , 82286-82293. [CrossRef]

30. Chi, P.-L.; Yang, T.; Tsai, T.-Y. A fully tunable two-pole bandpass filter. IEEE Microw. Wirel. Compon. Lett. 2015, 25, 292-294. [CrossRef]

31. Gomez-Garcia, R.; Munoz-Ferreras, J.-M.; Psychogiou, D. Fully-reconfigurable bandpass filter with static couplings and intrinsicswitching capabilities. In Proceedings of the 2017 IEEE MTT-S International Microwave Symposium (IMS), Honololu, HI, USA, 4-9 June 2017; pp. 914-917.

32. Li, C.; Bian, Y.; Li, G.; Wu, Y.; Wang, J.; Wang, X.; Zhang, X.; Xia, F.; Bai, D.; Sun, L.; et al. A tunable high temperature superconducting bandpass filter realized using semiconductor varactors. IEEE Trans. Appl. Supercond. 2014, 24, 1-5.

33. Gomez-Garcia, R.; Munoz-Ferreras, J.-M.; Psychogiou, D. Dual-behavior resonator-based fully reconfigurable input reflectionless bandpass filters. IEEE Microw. Wirel. Compon. Lett. 2019, 29, 35-37. [CrossRef]

34. Hsieh, L.-H.; Chang, K. Tunable microstrip bandpass filters with two transmission zeros. IEEE Trans. Microw. Theory Technol. 2003, 51, 520-525. [CrossRef]

35. Cho, Y.-H.; Rebeiz, G.M. Tunable 4-pole noncontiguous 0.7-2.1-GHz bandpass filters based on dual zero-value couplings. IEEE Trans. Microw. Theory Technol. 2015, 63, 1579-1586. [CrossRef]

36. Psychogiou, D.; Gomez-Garcia, R. Multi-mode-cavity-resonator-based bandpass filters with multiple levels of transfer-function adaptivity. IEEE Access 2019, 7, 24759-24765. [CrossRef]

37. Lee, T.-C.; Yang, W.; Peroulis, D. Reconfigurable filter design using resonators as coupling structures. In Proceedings of the 2015 IEEE MTT-S International Microwave Symposium, Phoenix, AZ, USA, 17-22 May 2015.

38. Zhao, K.; Gomez-Garcia, R.; Psychogiou, D. Tunable quasi-reflectionless bandpass filters using substrate integrated coaxial resonators. IEEE Trans. Circuits Syst. II Exp. Briefs 2022, 69, 379-383. [CrossRef]

39. Dishal, M. Design of dissipative band-pass filters producing desired exact amplitude-frequency characteristics. Proc. IRE 1949, 37, 1050-1069. [CrossRef]

40. Magnuski, M.; Wójcik, D.; Surma, M.; Noga, A. A compact widely tunable bandpass filter dedicated to preselectors. Electronics 2021, 10, 2315. [CrossRef] 